\title{
Los temas policiales y la violencia, los asuntos priorizados por el diario más exitoso de habla hispana
}

\section{Crime and violence, the issues prioritized by the most successful Spanish-language newspaper}

María Gabriela Villalobos León ${ }^{1}$

Universidad Peruana de Ciencias Aplicadas. Lima, Perú

villalobos.magaby@gmail.com

ORCID 0000-0002-7685-3283

Citar como: Colina, F. y Albites, J. (2020). Aprendizaje e innovación: retos en las organizaciones del siglo XXI. Desde el Sur, 12(1), pp. 177-200.

\section{RESUMEN}

El diario Trome es considerado un éxito periodístico y comercial. Es el diario de habla hispana de mayor venta de ejemplares al día y con el mayor alcance en lectoría. La presente investigación busca identificar cuál es la agenda informativa ofrecida a su lectoría y evidenciar las características preponderantes en sus representaciones sociales cotidianas. Para el análisis se revisó información sobre sus 18 años de circulación y se estudiaron 21 ediciones consecutivas, haciendo énfasis en los titulares de la noticia principal de la portada y en los de las secciones más extensas: «Actualidad» $y$ «Fiesta».

Se identificó que los temas policiales y las representaciones violentas se imponen en la agenda noticiosa y predominan como representaciones de la vida cotidiana. Así, vemos que el $100 \%$ de ejemplares analizados priorizan como titular principal en la portada una noticia vinculada a una situación de violencia o de conflicto; además, que el

1 Bachiller en Periodismo por la Universidad Peruana de Ciencias Aplicadas (2001) y candidata a la licenciatura (2020). Máster en Investigación Participativa para el Desarrollo Local por la Universidad Complutense de Madrid (2004-2005). Tiene estudios de Migraciones Internacionales en el Instituto de Estudios Políticos de París, Sciences Po (2020), y de Derechos Humanos de Niñas y Niños en la Universidad de Ginebra (2018). Cuenta con experiencia en la gestión de proyectos de cooperación internacional enfocados en la garantía de los derechos humanos, con énfasis en poblaciones vulnerables, en contextos de desarrollo y crisis humanitarias. 
$76 \%$ es de contenido policial, aunque el diario no cuenta con una sección de policiales.

\section{PALABRAS CLAVE}

Trome, éxito, violencia, policiales, agenda setting

\section{ABSTRACT}

The Trome newspaper is considered both a commercial and journalistic success. It is the biggest selling Spanishlanguage daily, with the largest readership. The aim of this study was to identify the type of stories prioritized by Trome, and to establish the principal characteristics underlying its portrayal of everyday life. For this analysis, information related to the publication's eighteen-year history was studied, together with twenty-one consecutive editions, while giving particular emphasis to their front page headlines, and those featuring in the paper's most extensive sections, namely "Actualidad" ("Current Affairs") and "Fiesta" ("Entertainment").

Our study determined that issues related to crime and violence predominate in the newspaper's depiction of everyday life; in fact, $100 \%$ of the editions analyzed prioritized in the form of a front page headline a story related to a situation involving violence or conflict. At the same time, $76 \%$ of the content in those editions analyzed focused on crime-related stories, despite the fact that the newspaper does not contain a crime section.

\section{KEYWORDS}

Trome, success, violence, crime, agenda setting

\section{Introducción}

Considerando el éxito periodístico y comercial del diario Trome, al ser el diario de mayor circulación de habla hispana - con una venta cercana a las 700000 copias cada día y un índice de lectores aproximado de 2500 000 (Quevedo, 2018, p. 2)—, la presente investigación busca identificar cuál es la agenda informativa ofrecida a su lectoría y evidenciar las características preponderantes en sus representaciones sociales cotidianas, o, como diría McCombs (2004, p. 24), cuál es la «realidad de segunda mano» construida especialmente para su público objetivo.

Este análisis es relevante, ya que el consumo de información tiene efectos permanentes y significativos en la vida de las personas y sus 
contextos. Es frecuente escuchar que los medios de comunicación son el cuarto poder. «Si alguna vez [...] el hombre tuvo una cosmovisión del mundo a través de sus creencias religiosas, hoy la tiene por intermedio de los medios masivos de comunicación» (Bein, 2003, p. 3). «Todo lo que sé es porque lo he leído en la prensa» es una cita al humorista norteamericano Will Roger (McCombs, 2004, p. 23) que expresa la capacidad de influencia y poder de los medios de comunicación frente a su audiencia, al configurar la agenda informativa diaria.

Antes de analizar la agenda informativa ofrecida por Trome a sus lectores, vamos a explorar cómo define el contenido de su agenda informativa diaria. Todo indica que su contenido informativo se desarrolla pensando en su público objetivo, es decir, en las familias de los niveles socioeconómicos más grandes en el país, C y D. En 2001, año de inicio del diario y cuando aún no se lograban las metas de circulación, en una de las discusiones del Comité de Gerencia de la empresa, Bernardo Roca Rey, director de publicaciones y multimedios, dijo: «Para mí, las ediciones que sacamos hasta el momento son demasiado serias para este público, no hay mucho contenido sobre espectáculo y no tienen muchas noticias locales que atraigan a los lectores, tal como estábamos esperando» (De Andrea, Silva y Prado, 2015, p. 133). En la misma línea, 12 años más adelante y ya con un diario con grandes ventas, el exdirector central de informaciones del diario El Comercio de Lima, Mario Cortijo, declaró que el éxito de los productos periodísticos del Grupo El Comercio (GEC) se debe a una clara segmentación de audiencias (ATDL, 2013, p. 6). En ese sentido, Carlos Espinoza, director de Trome, dijo que «cuando conoces bien a quién quieres llegar, puedes incluso conocer cómo piensa este grupo objetivo respecto a una noticia, y en este aspecto el periodista se convierte en un sociólogo que se identifica con su lector» (ATDL, 2013, p. 14).

Esa valorización del perfil de su audiencia para definir la agenda informativa del diario y sus buenos resultados comerciales y periodísticos - venta y lectoría - puede expresarse en el marco de dos conceptos postulados por el sociólogo francés Pierre Bourdieu, el habitus y el campo. Esto se debe a que el habitus se construye en la dialéctica entre lo que el consumidor considera su propia cultura, sus estilos, sus intereses y lo que el medio de comunicación define como la cultura, los estilos y los intereses de la audiencia a la que está dirigida el medio. Asimismo, el campo se define como la relación de una persona con las estructuras que percibe como propias - a las que pertenece, producto de una historia determinada - y que dependen, en gran parte, de cómo la persona se ubica o se percibe a sí misma (Pinto, 2002, p. 42). 
En esa línea vamos a plantear que el campo de la audiencia de Trome se ubica en el nivel socioeconómico $C$ y $D$, y que la agenda informativa y sus representaciones sociales están vinculadas a lo que se considera el habitus de ese campo. Es decir, la construcción informativa se basa en lo que se consideran las autopercepciones de los lectores sobre sus intereses y en la interpretación del diario sobre las características del lector. Como propone Pinto (2002): «pensar en términos de disposición, como nos invita a hacerlo la teoría del habitus, es ya, al menos en parte, pensar en términos de relación, puesto que, en el mundo social, ser es estar situado y situarse en un espacio diferenciado ajustándose a sus posibilidades propias, y solo a ellas» (p. 46). Y es así que la noción de habitus en sí misma le abre las puertas a la noción de campo.

\section{Materiales y métodos}

Para esta investigación se analizaron 21 ediciones consecutivas del diario Trome. Se definió analizar fechas consecutivas con el fin de identificar la tendencia en la cotidianidad. Además, se eligió el periodo entre el 11 y el 31 de mayo de 2019, ya que no hubo algún hecho externo e irregular que alterara la agenda informativa (por ejemplo, la Copa América o los Juegos Panamericanos y Parapanamericanos). Lo que sí hubo fue una celebración regular en el Día de la Madre.

En el análisis se hizo énfasis en las representaciones sociales cotidianas preponderantes del diario Trome expresadas en su portada, a través del titular principal, así como en las secciones más extensas del diario y, además, priorizadas en la portada; es decir, «Actualidad»y «Fiesta».

Realizar el análisis a través de la portada del diario es central. La portada es la puerta de entrada o de salida para decidir el consumo y la compra del diario; le da al lector la idea clara del tipo de contenido periodístico del diario. La portada puede llamar la atención del lector (en positivo) o chocar con sus valores y necesidades (Saint-Pierre, 2016, p. 1). Además, el foco del análisis está en los titulares, ya que, como plantean Díaz y Mellado (2017), «Los titulares y noticias centrales de los medios informativos son considerados los referentes de la máxima jerarquización de temas relevantes para ellos (Casero-Ripollés y López-Rabadán, 2012). A través de su contenido se pueden apreciar líneas editoriales y prioridades temáticas de fuerte influencia social al guiar la atención de la audiencia sobre un número reducido de tópicos» (p. 108).

En el marco de la investigación también se realizó un análisis de la evolución del diario en sus 18 años. Las discusiones de sus creadores y los ajustes al contenido periodístico y su narrativa bajo el argumento de ofrecer lo que su audiencia espera. 
Finalmente, para identificar las características preponderantes en la agenda informativa y en la construcción de las representaciones sociales cotidianas ofrecidas a su lectoría se elaboraron tres matrices de análisis de titulares y se definieron nueve variables. La primera matriz fue para el titular de la nota principal de la portada; la segunda matriz, para los titulares de la sección «Actualidad», y la tercera matriz, para los titulares de la sección «Fiesta».

Las variables de la matriz para el análisis de los 21 titulares de la noticia principal de las portadas fueron las siguientes:

- Variable 1: tipo de noticia.

- Variable 2: ¿está relacionada con alguna situación violenta o de conflicto?

- Variable 3: ¿está relacionada con alguna situación negativa?

- Variable 4: ¿se utiliza alguna jerga, apodo, adjetivo o peruanismo?

Las variables de la matriz para el análisis de los titulares de las 109 páginas de la sección «Actualidad» fueron las siguientes:

- Variable 5: ¿la mayoría de las noticias o un número igualitario en la página son de tipo policial?

- Variable 6: ¿la mayoría de las noticias o un número igualitario en la página se relacionan con alguna situación violenta o de conflicto?

- Variable 7: ¿la mayoría de las noticias o un número igualitario en la página se relacionan con alguna situación negativa?

Las variables para el análisis de los titulares de las 98 páginas de la sección «Fiesta» fueron las siguientes:

- Variable 8: ¿la mayoría de las noticias o un número igualitario se vinculan a la vida personal de algunos de los personajes?

- Variable 9: ¿la mayoría de las noticias o un número igualitario en la página se relacionan con alguna situación negativa o de conflicto?

Vale precisar que para la valoración de las variables $5,6,7,8$ y 9 se crearon dos códigos.

- El número cero significa que existe un número menor de noticias de corte policial en la página analizada.

- El número uno significa que existe un número igual o mayor de noticias de corte policial en la página analizada.

\section{Resultados}

El diario Trome fue puesto en circulación el 20 de junio de 2001. Desde la posición de sus dueños (Empresa Editora El Comercio), el motivo de su creación fue la necesidad de brindar información a los sectores 
socioeconómicos C y D, la nueva clase media (Mineo, 2014, p. 1). Luego de varios estudios de mercado, se decidió posicionarlo entre los diarios populares serios, como Correo, y los diarios chicha, como El Chino, La Chuchi, etc. (De Andrea et al., 2015, p. 131). Los primeros seis meses no lograron los resultados previstos (con un tiraje de 60000 , solo vendían 40 000 ejemplares al día), por lo que el Comité de Gerencia del diario acordó hacer ajustes (De Andrea et al., 2015, p. 125). Todo indica que uno de los cambios centrales fue la contratación del nuevo editor, Carlos Espinoza - exeditor de Ajá-y de otros profesionales con experiencia en lo que se denomina prensa popular. Luego de 18 años, ese equipo continúa en la dirección y el diario sigue siendo exitoso. Por ejemplo, el 3 de junio de 2019 fue la segunda vez que Trome agotó el tiraje de un millón de ejemplares.

El éxito de Trome es indiscutible y todos los involucrados directos se lo atribuyen a la misma razón, conocer a su audiencia y, basados en ese conocimiento, informarle lo que consideran le corresponde. Para Pedro José de Zavala, gerente de marketing del Grupo El Comercio, el éxito no se basa en la mezcla de los temas periodísticos, sino en que el periódico habla de los peruanos en el sector $C$; no muestra tanta sangre, tampoco tanta «piel», como otros diarios de su categoría, lo cual es clave para su ingreso en los hogares (Clases de Periodismo, 2013, párr. 4). Por su parte, María Elena Otiniano, investigadora de mercado en el Grupo El Comercio, no cree que la única razón del éxito sea que el diario ofrece premios semanales, becas y otras promociones. Ella piensa que el medio combina eficientemente las informaciones, con un buen porcentaje de «contenido emocional» (Clases de Periodismo, 2013, párr. 6). Y, finalmente, el director de Trome, Carlos Espinoza, piensa que el diario sigue siendo un éxito debido a que «ha evolucionado con la sociedad. El corazón del periódico son sus periodistas, que tienen a su público en la cabeza: la clase media que busca el progreso y mejorar su calidad de vida [...] Como periodistas tenemos que adaptarnos a los cambios [...] Ahora hay más conciencia en temas como el medioambiente, la contaminación, el respeto a la mujer, la igualdad de oportunidades para todos» (Clases de Periodismo, 2013, párr. 9). Es así que Trome se posicionó como el diario que conocía realmente a la gente, sabía lo que vivía y lo que esperaba; conocía a la familia y por eso tenía lo que en verdad era importante para ella (Mayorga, Araujo y Schwalb, 2005, pp. 81-83).

Teniendo eso en mente, veamos qué contenidos prioriza en su agenda informativa y qué representaciones sociales de la cotidianidad brinda a su lectoría. El hallazgo general más relevante y central es que Trome ofrece prioritariamente a su lectoría una agenda informativa vinculada a temas policiales, situaciones de violencia, de conflicto y negativas; y que 
el segundo tema destacado se relaciona con asuntos de la vida privada de personajes de la farándula.

A continuación, veremos el detalle del análisis:

\section{La portada}

El diario Trome tiene normalmente cuatro noticias en portada. La principal ocupa un $60 \%$ de la página. Al analizar el titular de la noticia principal (variable 1) se encontró que el $76 \%$ de ejemplares (16 de los 21 ) prioriza una noticia con contenido policial y violento, incluso cuando se tratan temas vinculados a la política o el espectáculo. El resto de los titulares se vinculan a temas de espectáculo (14\%), políticos (5\%) y a un desastre por fenómeno natural (5\%).

TABLA 1. Muestra de análisis de la variable 1

\begin{tabular}{cc} 
Titular principal de la portada & $\begin{array}{c}\text { Tipo de noticia } \\
\text { Variable 1 } \\
\text { Número de noticias }\end{array}$ \\
\hline Tipo de titular & 10 \\
\hline Policial & 5 \\
\hline Policial político & 1 \\
\hline Policial espectáculo & 1 \\
\hline Político & 3 \\
\hline Espectáculo & 1 \\
\hline Desastre & 21 \\
\hline Total
\end{tabular}

Además, dentro de los 16 ejemplares que priorizan en el titular principal de la portada alguna noticia con contenido policial y violento, 10 de ellos priorizan una noticia de corte policial, es decir, tienen como nota más importante un suceso policial violento donde los personajes de la historia son desconocidos. Considerando la preponderancia de noticias de corte policial, es interesante constatar que el diario no tiene una sección llamada «Policiales» y que las noticias con ese contenido son desarrolladas en la sección «Actualidad».

A continuación, en la tabla 2, una muestra de la clasificación del titular principal de la portada según la variable 1 . 
TABLA 2. Muestra de análisis de la variable 1

Titular principal de la portada

Tipo de noticia

Variable 1

12 de mayo

Vanessa llora por «Ken»

Actriz sufre crisis emocional por matrimonio que solo duró ocho meses

Se irá a México para olvidar a alcalde

13 de mayo (infografía)

Policial

A balazos matan a 3 amigos

Asesinos en moto y carro dispararon 15 veces a obreros

Policía sospecha de guerra de cupos en Los Olivos

14 de mayo (infografía)

Policial

"Gordo» en crimen de esposos y empleada

Policía sospecha que los habría matado porque no aceptaba relación con su hija

Víctimas fueron baleadas en la cabeza y casa fue incendiada en La Molina

Cámaras lo grabaron en vivienda, pero él niega triple asesinato

\section{5 de mayo}

10 millones mandan a la cárcel a Susana

Juez dictó 18 meses de prisión preventiva para «Tía Regia» de 69 años

La trasladaron enmarrocada a calabozo

Investigan si se quedó con dinero que no se usó en campaña del «No»
Espectáculo

Un segundo hallazgo en el análisis de los titulares de la noticia principal de la portada es que el $100 \%$ se relaciona con alguna situación violenta o de conflicto (variable 2) o alguna situación negativa (variable 3), incluso cuando el titular está vinculado al espectáculo, temas políticos o a un desastre por fenómeno natural, o cuando se plantea un final feliz (por ejemplo, cuando atrapan a los delincuentes). 
TABLA 3. Muestra de análisis de las variables 2 y 3

\begin{tabular}{|c|c|c|}
\hline Titular principal de la portada & $\begin{array}{l}\text { ¿Está relacionada } \\
\text { con alguna } \\
\text { situación violenta } \\
\text { o de conflicto? } \\
\text { Variable } 2\end{array}$ & $\begin{array}{c}\text { ¿Está } \\
\text { relacionada con } \\
\text { alguna situación } \\
\text { negativa? } \\
\text { Variable } 3\end{array}$ \\
\hline $\begin{array}{l}17 \text { de mayo } \\
\text { Fue un golpe muy duro } \\
\text { «Ken» Forsyth dice que había programado su vida con } \\
\text { Vanessa y tener hijos } \\
\text { Reitera que le faltó tiempo para su matrimonio }\end{array}$ & Sí & Sí \\
\hline $\begin{array}{l}18 \text { de mayo } \\
\text { Trepan paredes y chapan a } 3 \text { rateros } \\
\text { Policías allanaron vivienda, en Puente Piedra, donde } \\
\text { desmantelaban camionetas y autos robados } \\
\text { «Pochito», «Loco»y «Fer» fueron sorprendidos y terminaron } \\
\text { en el piso }\end{array}$ & Sí & Sí \\
\hline $\begin{array}{l}19 \text { de mayo } \\
\text { Mano dura contra corruptos } \\
\text { Entrevista exclusiva a fiscal José Domingo Pérez } \\
\text { Afirma que le sorprendió la muerte de Alan, pero «Los } \\
\text { fiscales tienen que hacer respetar la ley» } \\
\text { Cuenta que duerme tranquilo porque cumple con su trabajo } \\
\text { Dice que la corrupción es un cáncer que hace daño al país } \\
\text { Es hincha de Paolo Guerrero y también jugó de delantero }\end{array}$ & Sí & Sí \\
\hline
\end{tabular}

En la misma línea, las palabras utilizadas para redactar el titular principal de la portada son de tono negativo y violento. No existe una diferencia relevante según el tipo de noticia (policial, espectáculo, política, etc.).

TABLA 4. Muestra de palabras utilizadas en el titular principal de la portada policial

\begin{tabular}{|c|c|c|}
\hline Amordazado & Encapuchados & Delincuentes \\
\hline Terror & Venganza & Pistoleros \\
\hline Armas & Prenderle fuego & Amenazaba \\
\hline Asesinato & Golpe & Cárcel \\
\hline Pistoleros & Balazos & Prisión \\
\hline Enmarrocada & Encerrada & Penal \\
\hline Corruptos & Muerte & Cáncer \\
\hline Corrupción & Abusivos & Roban \\
\hline Manosean & Pistoleros & Tocamientos indebidos \\
\hline Blindar & Matan & Acuchillado \\
\hline
\end{tabular}


TABLA 5. Muestra de palabras utilizadas en el titular principal de la portada no policial

\begin{tabular}{lll} 
Llora & $\frac{\text { Crisis emocional }}{\text { Gechar }}$ & $\frac{\text { Damnificados }}{\text { Plata }}$ \\
\hline No es interesada & Derrumbados & Muerto \\
\hline Heridos & Destruidas \\
\hline
\end{tabular}

Otro elemento que contribuye con el ambiente violento y negativo es que el lenguaje utilizado es bastante descriptivo, pero a la vez directo, por lo que permite imaginar con facilidad los hechos y a los personajes involucrados:

- ¡Atrapen a los asesinos! (20/5/19)

- Trepan paredes y chapan a 3 rateros (18/5/19)

- Pánico en la madrugada (27/5/19)

- 20 balazos por drogas (28/5/19)

- 35 años para asesino de Eyvi (29/5/19)

Además, el titular principal de portada se escribe normalmente en letras rojas, de tamaño muy grande (parecido al del nombre del diario), y es una oración corta, directa al suceso.

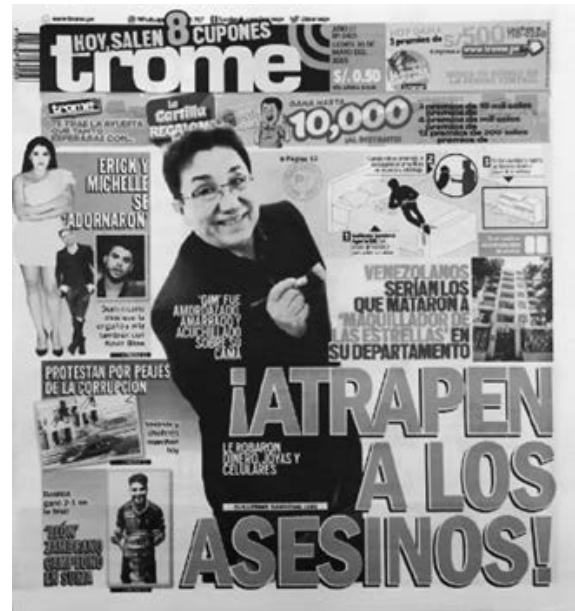

FIGURA 1. Portada de Trome, 20/5/2019 
Otro elemento que destaca en los titulares es el uso del lenguaje coloquial, las jergas, los apelativos y los peruanismos (variable 4). Haciendo eco a lo que le comenta el fotógrafo Gary a María en su columna del 26 de abril de 2014 en Trome, «el peruano siempre ha destacado por su imaginación y esa característica se expresa en el lenguaje. Inventamos una enorme cantidad de palabras, expresiones».

- Matan a «raquetero» y chapan a dos (11/5/2019)

- «Pochito», «Loco»y «Fer» fueron sorprendidos y terminaron en el piso $(18 / 5 / 2019)$

- Vizcarra fue a «pechar» a parlamentarios y les exige no hacer trampas por la reforma política (22/5/2019)

- Tiembla el «Gordito». Expresidente de la Federación Peruana de Fútbol está preso en Chiclayo por caso "Los Wachiturros de Tumán» $(24 / 5 / 2019)$

- El fallecido es el «Negro Paz» y policía sospecha de una venganza de «Chino». Atacaron a víctimas cuando se divertían en una cebichada (28/5/2019)

- Policía da golpe a 3 «marcas». Capturan a balazos a banda del feroz «Cara de Jarra» (31/5/2019)

\section{La sección «Actualidad»}

En «Actualidad», Trome incluye entre cuatro y seis páginas y, normalmente, una de las primeras se dedica a los premios y concursos que promueve el diario. Las otras páginas, en su mayoría, incluyen noticias policiales o hechos violentos. Así, el $45 \%$ de las páginas analizadas (49 de 109 ) incluyen un número mayor o igual de noticias de corte policial en relación con las otras noticias desarrolladas (variable 5). Ver una muestra en la tabla 6. 
TABLA 6. Muestra de análisis de la variable 5

Titulares de las páginas de «Actualidad» del 31/5/2019

Variable 5

P. 10

«Cara de Jarra» salió de "Luri» para asaltar tiendas

Pistoleros piden menú y roban restaurante

Pareja asesina a recepcionista de hostal

Caen extorsionando a empresario

P. 12

Bombazos en marcha contra peajes

Sospechosos de crimen se dan la gran vida

20 mil alumnos de Telesup en el aire

A participar en el simulacro de sismo

Amplían cárcel a Susana

P. 14

Se estaba traficando con la justicia

Vizcarra: vamos a combatir la corrupción

Fujimoristas se sienten ofendidos

Cierre del Congreso enfrenta a juristas

Se aferran a inmunidad parlamentaria

P. 16

Harán carrera por atletas de Juegos Panamericanos

Extraen tumor gigante de cerebro

A balazos se meten a mercado y asaltan avícola

Calientitos para el frío

Taxista ladrón dopaba a pasajeros

Pistoleros acribillan a menor de 15 años

Roban tienda por cuarta vez

P. 18

Gemelos ganan Beca 18

Atrapan a «Venecos del Terror»

A modo de detalle, en la tabla 7 vemos los titulares de cuatro de las cinco páginas de la sección «Actualidad» del 14 de mayo de 2019 (se ha excluido la página de los premios y concursos del diario). De las 20 noticias publicadas, solo dos no son de corte policial. 
TABLA 7. Muestra de análisis al detalle de la variable 5

Titulares de las páginas de la sección «Actualidad» del 14/5/2019

P. 4

«Gordo» en crimen de esposos y empleada. Asegura que es inocente pero policía cree que actuó en venganza porque ancianos no aceptaban relación con su hija

Hallan sin vida a policía retirado

Matan a venezolano

Atrapan a «Diablillo» [ladrón]

P. 8

Susana Villarán: Preparada para ir a prisión

Lo limpian de «mamanivideos»

Mark Vito asustado

Historias nunca contadas [columna de Miguel Ramírez]. La tardía confesión de Susana Villarán

P. 10

Gamarra está bonita, limpia y segura

Taxista arrastra con su carro a policía

Profesor es el «Rey de la Plastilina»

Acusan de violación a pastor

Miles en todo el Perú. Bloquean carreteras en paro de agricultores

P. 12

¡Cadena perpetua para monstruo! Cientos de pobladores en velorio de niñas violadas y asesinadas

Rescatan pato vivo en desagüe

Metía droga en papas rellenas

Se suicida lanzándose de cabeza desde el puente

Niño iba en bicicleta y carro lo deja grave. Lo arrastró

Falso inspector pedía plata a comerciantes

Levantador de pesas cae en marihuana

Por otro lado, 67 páginas de las 109 analizadas (el 61\%) incluyen un número mayor o igualitario de noticias relacionadas con alguna situación violenta o de conflicto (variable 6). Por ejemplo, en la edición del 15 de mayo solo cuatro titulares de los 21 publicados, en cinco de las seis páginas de la sección «Actualidad», no están vinculados a situaciones violentas o de conflicto (se ha excluido la página de los premios y concursos del diario) (ver tabla 8). 
TABLA 8. Muestra de análisis de la variable 6

Titulares de las páginas de la sección «Actualidad» del 15/5/2019

Variable 6

P. 9

Bello pato del amor en Huachipa

Vencidos. Cosméticos malograban la piel

Crean banco de leche materna

P. 10

Susana se va presa

Chalán Nava ruega por libertad

P. 12

Primos policías y madrina mueren en choque

Acorralan a Gordo por triple crimen

Se lanza de tercer piso

Atropelló a mujer en venganza

P. 14

Se alistan para alentar a la selección

Incendio en avenida Larco

Se llevó 350 mil soles y salva de la cárcel

Andahuaylas llora a víctimas de «monstruo»

Cuidado con balones de gas adulterados

Hellboy paseó por Lima

P. 16

Llama del amor se apaga rápido

Princesa enamorada de un chamán

Robots imitan a insectos $y$ aves

Detienen a profesor por chat erótico

Mujer se mete debajo de camión

Allanan casas por Peter Ferrari

La última variable analizada en los titulares de la sección «Actualidad» es la número 7, que responde a la pregunta: «¿La mayoría de las noticias o un numero igualitario en la página se relacionan con alguna situación negativa?». En total, 67 de las 109 páginas analizadas (el 61\%) incluye en cada página un número mayor o igualitario de noticias relacionadas con alguna situación negativa. En la tabla 9 se puede ver una muestra del análisis de la variable 7. 
TABLA 9. Muestra de análisis de la variable 7

Titulares de las páginas de la sección «Actualidad» del 16/5/2019

Variable 7

P. 4

Asaltan hotel y los atrapan a balazos

Capturan a sospechoso de 2 crímenes

Asesinan a albañil

Robaron a su vecino

Acosaba a niñas por redes

P. 7

Emoliente buenazo contra el frío

Caos por cierre de avenida

Chapan a prima de «La Bestia»

P. 10

Clase media se va para arriba

Repuntó economía

Padres deben imponer autoridad sin violencia

Denuncian robo de 29 millones en banco

Podrían anular peajes de la corrupción

Reapareció Humala

P. 12

Distinguen a médico de 100 años

Paciente de EsSalud se suicida en hospital

Fiscal Zoraida Ávalos denuncia a Chávarry

Mucho cuidado con la presión alta

Empleada secuestró a bebita

Venezolano era extorsionador

Caen con metralleta y 5 pistolas en Sayán

P. 13

Roban a autor de «Muchacho provinciano»

Para mostrar algunos detalles de la variable 7 podemos revisar la tabla 10 con los titulares de cuatro de las cinco páginas de la sección «Actualidad» de la edición de Trome del 11 de mayo de 2019 (se ha excluido la página de premios y concursos del diario). Se aprecia que, de las 17 noticias publicadas, solo dos no expresan una situación negativa (el 12\%). 
TABLA 10. Muestra de análisis al detalle de la variable 7

Titulares de las páginas de la sección «Actualidad» del 21/5/2019

P. 4

Fiscalía investiga a futbolistas por violación

Asesinan a joven con 20 balazos delante de su mamá

Roba auto y lo chapan

Tráiler mata a barrendera

\section{P. 8}

Bajan el dedo a Chávarry

Salaverry: Están negociando mi cabeza

Yesenia en la mira

Historias nunca contadas: Yeni Vilcatoma en cinta

P. 10

Marchan contra peajes de la corrupción

Alcalde Jorge Muñoz dijo que las concesiones están manchadas y no pueden seguir como están Usuarios de celulares Huawei preocupados

Mujer mata a sus 2 hijos con ácido muriático

Hermano de exministro puede ir a la cárcel

Hinostroza se corre de extradición

P. 13

A celebrar el Día de la Papa

Robó 250 mil soles para darle regalos a su suegra

Concurso emprendedor

Finalmente, a modo de ilustración, en la tabla 11 se muestra un listado de algunas palabras utilizadas en los titulares de las páginas de la sección «Actualidad». Es importante identificar el tipo de lenguaje empleado para determinar si es una expresión de la violencia verbal. «Este tipo de violencia verbal es menos perceptible que la violencia física, pero con efectos mucho más graves; podemos llegar a aterrarnos por la violencia física, pero no por las agresiones verbales» (Cebrián, 2006, p. 2). «No hay duda de que las palabras pueden convertirse en instrumentos cargados de significación [...] porque tienen significados profundos, que reflejan intenciones latentes y conforman nuestra manera de pensar, de comunicarnos y de actuar» (Fernández, 2009, p. 196). 
TABLA 11. Palabras utilizadas en los titulares de «Actualidad»

\begin{tabular}{llll} 
Mata & Monstruo & Aprietan el cuello & Secuestró \\
\hline Extorsión & Lincharlo & Extorsionando & Metralleta \\
\hline Incautan & Extorsionador & Puñetazos & Escándalo \\
\hline Diablo & Narcotráfico & Voraz & Tragedia \\
\hline Suicida & Robacarros & Dopaba & Balean \\
\hline Amenazas & Secuestran & Pedófilos & Mafia \\
\hline Atacó & Torturan & Sicarios & Cuchilladas \\
\hline Terror & Crimen & Pistoleros & Golpea \\
\hline Muere & Sin vida & Atropelló & Sicario \\
\hline Asaltantes & Venganza & Pánico & Captura \\
\hline Ratas & Asustado & Destrozos & Asfixian \\
\hline Pistoleros & Masacre & Acribillan & Peperas \\
\hline Armas & Vándalos & Raqueteros & Prostíbulos \\
\hline Buitres & Violadas & Lloran & Droga \\
\hline Gatillero & Asesinadas & Terrorismo & Cárcel \\
\hline
\end{tabular}

\section{La sección «Fiesta»}

Para el caso de la sección «Fiesta» se han analizado 98 páginas de 21 ediciones consecutivas de Trome. Normalmente esta sección incluye entre cuatro y seis páginas. En una de ellas, frecuentemente la última, se presenta una carta con problemas de amor dirigida a la doctora Carmen y la respuesta correspondiente con consejos para superar la situación que atraviesa el remitente. Además, en esa página se incluye el horóscopo, el crucigrama «Puras Letras» y otras pequeñas notas como «Un día como hoy». A diferencia de la página descrita, el resto en su mayoría informa sobre asuntos de la vida privada de personajes vinculados a programas de televisión como realities, concursos, cómicos y de chismes.

Así, el 97\% de las páginas de la sección «Fiesta» (95 de las 98 revisadas) tiene un número mayor o igual de titulares sobre noticias vinculadas a la vida personal de personajes del espectáculo y de algún anónimo, como en la carta dirigida a la doctora Carmen (variable 8).

A modo de ejemplo, en la tabla 12 se observa que en la edición del 11 de mayo todas las páginas de la sección «Fiesta» tienen un número igual o mayor de noticias vinculadas a asuntos de la vida privada, y que de las 16 noticias publicadas solo dos no se vinculan a asuntos personales. Es decir, el $87 \%$ tienen contenido vinculado a la vida privada de personajes públicos. Se excluye la página de la carta a la doctora Carmen. 
TABLA 12. Muestra de análisis al detalle de la variable 8

Titulares de las páginas de la sección «Fiesta» del 11/05/2019

P. 24

Nicola: Romina confía en mí

Paula no teme a críticas

Flavia se vistió de novia

Verónica llama a la cigüeña

P. 25

Alessandra es feliz soltera

Renzo dice adiós a realities

Lucía: De amor nadie se muere

P. 26

Tiene 7 meses de embarazo y sería una niña. Fiorella en los descuentos

Milena: Mi hija sufre por Edwin

Melissa: La verdad salió a la luz

Silvia superó crisis con esposo

Ampay [chismes]

P. 28

Stephanie: Tengo miedo a enamorarme

Tilsa Lozano echa a Magaly

Monique hará locuras en Nueva York

Susan brilló en Chile

Vale resaltar que en la mayoría de las noticias sobre asuntos personales hay una fuente identificada o abierta de la que proviene la información; es decir, no es un chisme o una noticia sin confirmar. En el titular se utiliza, regularmente al inicio, el nombre de la persona sobre la que se informa y la fuente de información. Por ejemplo:

- Ivana: Farfán me propuso vivir en Rusia (12/5/2019)

- Magaly: Pavón es un vulgar patán (14/5/2019)

- Melissa: «Coto» no es mi «paño de lágrimas» (15/5/2019)

- Romina: Angie y yo no tenemos problemas (16/5/2019)

- Melcochita: Yahaira es más guapa que Melissa (19/5/2019)

- Emanuel: Mi novia no es celosa (21/5/2019)

- Josimar: La tormenta ya pasó (22/5/2019)

Por otro lado, al analizar la variable 9 se ha identificado que 37 páginas de las 98 analizadas (el 38\%) incluyen un número mayor o igual de noticias vinculadas a alguna situación negativa o de conflicto.

Por ejemplo, en la tabla 13 de la sección «Fiesta» del 17 de mayo, tres de las cuatro páginas tienen un número mayor o igual de noticias vinculadas 
a alguna situación negativa o de conflicto. Además, de las 11 noticias publicadas, el $82 \%$ cumple la misma regla. Solo dos no están vinculadas a una situación negativa o de conflicto. Se excluye la página de la carta de amor dirigida a la doctora Carmen.

TABLA 13. Muestra de análisis al detalle de la variable 9

Titulares de las páginas de la sección «Fiesta» del 17/5/2019

\section{P. 36}

Erick: Michelle me hizo brujería

Nataniel se lanza a cantar

Shirley en coqueteos con Ray Sandoval (no expondrá su relación porque ya la pasó mal)

Luciana y Emilio niegan crisis en su relación

Ampay

P. 38

Tilsa amenaza al «Loco»

Rous llama soberbia a Ivana

Kate se enfrenta a Susan

"Yo tengo códigos». Carlos Vílchez aclara que nunca se ha metido con la hermana o expareja de un amigo

P. 40

Giovanna cerró un ciclo [programas cómicos]

Peluchín jala orejas a Pavón

Finalmente, resulta interesante el lenguaje utilizado en esta sección. Por un lado, se diferencia de la sección «Actualidad» por el empleo de palabras vinculadas a la vida de pareja, familiar y a las relaciones interpersonales. Por otro lado, se asemeja en el uso de un lenguaje coloquial y jergas, $y$, en algunos casos, palabras con un tono negativo, de conflicto y violento. A continuación, en la tabla 14 , un listado de algunas de las palabras utilizadas en la sección «Fiesta».

TABLA 14. Muestra de palabras utilizadas en la sección «Fiesta»

\begin{tabular}{llll} 
Confía & Acoso & Bañada en aceite & No aguanta pulgas \\
\hline Novia/o & Esposo & Raja & Cerré la fábrica \\
\hline Feliz & Cuadra & Colgué los chimpunes & Se pone la camiseta \\
\hline Soltera & Enamorarme & Hace la cruz & Chihuanes \\
\hline Amor & Cirugía & Pone el parche & Gallo ponedor \\
\hline Mentirosa & Celaba & Ya salió de las canchas & Se adornaron \\
\hline Infiel & Bautizó & Suelto en plaza & Baja el dedo \\
\hline Soberbia & Interesada & Me saqué la lotería & Paño de lágrimas \\
\hline Decepcionado & Curvas & Fiesta en paz & En el partidor \\
\hline
\end{tabular}




\section{Discusión}

Tal como se ha evidenciado en la presente investigación, el tema priorizado en la agenda informativa del diario Trome responde mayoritariamente a hechos policiales $y$, en segundo lugar, a asuntos de la vida privada de personajes del espectáculo. Los temas minoritarios están vinculados a la política o a otros asuntos de la ciudad. Además, las representaciones sociales preponderantes están vinculadas a situaciones de violencia, negativas y de conflicto.

Es más, no solo las representaciones de la vida cotidiana, expresadas mayoritariamente en la portada y en la sección «Actualidad», están vinculadas a hechos violentos y negativos: el lenguaje utilizado regularmente también es violento y negativo. Inclusive en la sección «Fiesta», cuyo nombre expresa aspectos positivos como celebración y diversión, un poco más del tercio de sus páginas tienen un número mayor o igual de noticias vinculadas a alguna situación negativa o de conflicto expresadas con palabras de tono negativo y violento.

En este contexto llama la atención que, a pesar de la prioridad dada a los temas policiales y a la alta frecuencia de las noticias publicadas de este tipo, no exista explícitamente una sección policial en el diario y que las noticias policiales se informen en la sección «Actualidad». También resalta que el contenido preponderante de la sección «Fiesta», que podría equipararse con la sección de espectáculos de otros diarios, esté vinculado a hechos sin ninguna relevancia pública y colectiva, ya que se refieren a la vida privada de personajes de la televisión, básicamente asociados a programas de concursos, cómicos, realities y de chisme.

Considerando lo expuesto, y reconociendo que el diario Trome es un éxito como negocio, por su venta y publicidad, y también como producto periodístico, por su nivel de lectoría y sus 18 años de circulación, es una alerta identificar la alta carga de violencia y de temas de la vida privada priorizados en su agenda informativa; más aún si ese éxito - tanto desde la perspectiva de sus creadores y de su equipo periodístico, así como desde el resultado de diversos análisis - se debe al diseño ad hoc de su contenido para responder a las demandas de su público objetivo, las familias de los niveles socioeconómicos $C$ y $D$. En otras palabras, se podría decir que las representaciones de la vida cotidiana priorizadas en Trome se construyen según lo que consideran corresponde al habitus de su audiencia y al campo de esta, es decir, la «posición objetiva [...] dentro de la estructura social» (Aquileana, 2008, p. 1).

En ese sentido, como proponen Del Valle, Mayorga y Valdebenito (2010, p. 180), nos deberíamos preguntar cómo las representaciones 
sociales ofrecidas por Trome inciden en la visión de la realidad de su audiencia y cómo esta visión influye en sus prácticas cotidianas. Queda pendiente observar críticamente si el discurso de Trome refuerza el orden social (Del Valle, Mayorga y Valdebenito, 2010, p. 186) y una visión sesgada de la realidad para su audiencia. Sea como lo planteó Bernard Cohen: «Puede que la prensa no tenga mucho éxito en indicar a la gente qué pensar, pero tiene un éxito sorprendente en decirles a sus lectores sobre qué pensar» (Ferman, 2015, párr. 7), o como propone McCombs: «Las noticias no solo nos dicen sobre qué pensar sino cómo pensarlo» (Ferman, 2015, párr. 9), lo cierto es que "Lo que es "real" para un monje del Tíbet puede no ser "real" para un hombre de negocios norteamericano", por lo que "las acumulaciones específicas de "realidad" y "conocimiento" pertenecen a contextos sociales específicos» (Berger y Luckman, 2003, p. 13).

De otro lado, también queda pendiente profundizar sobre el potencial efecto de la cotidianidad de la violencia ofrecida en su agenda informativa a las familias que lo consumen. «La normalización de la violencia, además de los graves daños que ocasiona a la salud mental colectiva, hace que cada vez más personas mantengan un discurso donde la idea de violencia es lo central, y solo una minoría cada vez más pronunciada se pregunta críticamente ¿qué es?, ¿cómo opera y a quiénes beneficia la violencia y el miedo generalizado?» (Díaz, 2016, párr. 5). Tal vez la violencia cotidiana ofrecida en la agenda informativa «normaliza las pequeñas brutalidades y el terror en el ámbito de la comunidad y crea un sentido común de la violencia» (Ferrándiz y Feixa, 2014, p. 163).

Si bien la agenda informativa de Trome se basa en hechos reales, podrían incorporar en su priorización de noticias otras temáticas. Como proponen Díaz y Mellado (2017), la prensa impresa, elaborada para audiencias específicas, debería asegurar que su lectoría tenga una percepción pluralista y equilibrada de la realidad, ya que su oferta informativa influye en las prioridades y preocupaciones de los ciudadanos y ciudadanas.

\section{Contribución del autor}

María Gabriela Villalobos León ha participado en la concepción, la recolección de datos, la redacción y la aprobación de la versión final del artículo.

\section{Fuente de financiamiento}

Autofinanciado.

\section{Conflicto de interés}

La autora declara no tener conflictos de interés. 


\section{REFERENCIAS BIBLIOGRÁFICAS}

Asociación Peruana de Empresas de Investigación de Mercados, APEIM (2016). Los niveles socioeconómicos en el Perú. Recuperado de https:// breaketingnews.wordpress.com/2017/02/05/nse-en-peru/

Aquileana (2008). Pierre Bourdieu: «Concepto de habitus». La Audacia de Aquiles [blog]. Recuperado de https://aquileana.wordpress. com/2008/05/22/pierre-bourdieu-concepto-de-habitus/

ATDL. Intercambio Técnico (2013). Especial. Visita diarios asociados. Entrevista con Jorge Calderón. ATDL. Intercambio Técnico, 115, pp. 9-12. Recuperado de https://www.atdl.org/images/upload/revista/edicion/115/revista_115.pdf

ATDL. Intercambio Técnico (2013). Entrevista. Seminario anual Santiago de Chile. Ignacio Prado, presidente de la ATDL. ATDL. Intercambio Técnico, 115, p. 16. Recuperado de https://www.atdl.org/images/upload/revista/ edicion/115/revista_115.pdf

Bein, F. (2003). Periodismo y discriminación. El poder del lenguaje. La Guirnalda Polar, 78. Recuperado de http://lgpolar.com/page/read/381

Béjar, H., Adrianzén, A., Hildebrandt, C., Gargurevich, J., Tapia, G., Orrillo, W. y Lévano, C. (2008). Poder mediático. Lima: Fondo Editorial de la Universidad de Ciencias y Humanidades.

Berger, P. y Luckmann, T. (2003). La construcción social de la realidad. Buenos Aires: Amorrortu Editores.

Cebrián, S. (2006). Violencia verbal en los medios de comunicación y estrategias para reducirla. Jornades de Foment de la Investigació. Recuperado de http://repositori.uji.es/xmlui/handle/10234/78611

Compañía Peruana de Estudios de Mercado y Opinión Pública (2017). Estudio de lectoría de diarios en Lima y 15 principales ciudades. 2016. Recuperado de https://cpi.pe/images/upload/paginaweb/archivo/23/LectoriaDiarios_2016.pdf

Compañía Peruana de Estudios de Mercado y Opinión Pública (2016). Perú: población 2019. Recuperado de http://cpi.pe/images/upload/paginaweb/archivo/26/mr_poblacional_peru_201905.pdf

D’Andrea, G., Silva, J. y Prado, M. (2009). Trome: noticias para la base de la pirámide [caso de estudio de la Universidad Austral de Buenos Aires]. Recuperado de https://fr.scribd.com/document/390157755/1-Trome-Noticias-para-labase- de-la-piramide-1-1-pdf 
Del Valle, C., Mayorga, A. y Valdebenito, L (2010). Prensa, justicia y producción narrativa del poder: fundamentos teórico-metodológicos para un estudio comparado del discurso. Convergencia, 17(54). Recuperado de http://www.scielo.org.mx/scielo.php?script=sci_arttext\&pid $=$ S1405-14352010000300009

Díaz, M. (2016). Violencia social, violencia discursiva. Recuperado de https://www.revistafactum.com/violencia-social-violencia-discursiva/

Díaz, M. y Mellado, C. (2017). Agenda y uso de fuentes en los titulares y noticias centrales de los medios informativos chilenos. Un estudio de la prensa impresa, online, radio y televisión. Cuadernos. Info, 40. Recuperado de https://doi.org/10.7764/cdi.40.1106

Ferman, A. (2015). Teorías: agenda-setting vs autocomunicación de las masas. Recuperado de https://aleeferman.wordpress.com/2015/11/23/ teorias-agenda-setting-vs-auto-comunicacion-de-las-masas/

Fernández, M. (2009). Lenguaje violento en los medios de comunicación españoles. Recuperado de https://dialnet.unirioja.es/servlet/ articulo?codigo $=3825956$

Ferrándiz, F. y Feixa, C. (2004). Una mirada antropológica sobre las violencias. Alteridades, 14(27). Recuperado de https://www.redalyc.org/articulo. oa?id=74702710

García, O., Berríos, M., Briceño, M. y Berríos, F. (2011). Detrás de la titulación impresa. Recuperado de https://repositorio.flacsoandes.edu.ec/bitstream/10469/5389/1/RFLACSO-CH113-07-Garcia.pdf

Mayorga, D. (Ed.) (2008). Las mejores prácticas del márketing. Casos ganadores de los premios Effie. Perú. 2008. Lima: Universidad del Pacífico. Recuperado de https://studylib.es/doc/6019425/ver--abrir---repositorio-de-launiversidad-del-pac\%C3\%ADfico

McCombs, M. (2004). Estableciendo la agenda. El impacto de los medios en la opinión pública y en el conocimiento. España: Paidós.

Mineo, L. (2014). El diario más vendido en el mundo de habla hispana se hace en Perú. ReVista. Harvard Review of Latin America. Recuperado de https://revista.drclas.harvard.edu/book/el-diario-m\%C3\%A1s-vendidoen-el-mundo-de-habla-hispana-se-hace-en-per\%C3\%BA-0

Pinto, L. (2002). Pierre Bourdieu y la teoría del mundo social. Recuperado de https://www.academia.edu/15391345/LA_TEOR\%C3\%8DA_DEL_ MUNDO_SOCIAL._PIERRE_BOURDIEU

Quevedo, M. (2018). Culture and narrative in Peru's largest circulation tabloid. A social semiotic approach. Recuperado de http://mariainesquevedo.academia.edu/research 
Redacción Gestión (15/10/2013). Trome: la estrategia para convertir un diario en el más leído de habla hispana. Recuperado de https://gestion. pe/economia/empresas/trome-estrategia-convertir-diario-leido-hablahispana-50470

Redacción Trome (26/4/2014). Peruanismos. Recuperado de http://archivo.trome.pe/columnas/peruanismos-2005470

Fecha de recepción: 15/1/2020

Fecha de aceptación: 20/3/2020 